\title{
Active Traffic Management as a Tool for Addressing Traffic Congestion
}

\author{
Virginia P. Sisiopiku \\ University of Alabama at Birmingham \\ USA
}

\section{Introduction}

Recurrent and non-recurrent congestion in urban areas continues to be a major concern due to its adverse impacts on delays, fuel consumption and pollution, driver frustration, and traffic safety. In the U.S., limited public funding for roadway expansion and improvement projects, coupled with continued growth in travel along congested urban freeway corridors, creates a pressing need for innovative congestion management approaches.

Congestion management is certainly not a new concept. Strategies targeting demand management in response to recurrent congestion have been utilized for years. Examples include ramp metering, high occupancy vehicle (HOV) lanes and value pricing options. Other strategies focus on operational management such as incident detection and management in response to nonrecurring congestion. Many of these strategies rely on Intelligent Transportation Systems (ITS) for surveillance, congestion monitoring, and information dessemination and aim at increasing operational efficiency of existing systems.

Active Traffic Management (ATM) is a new approach that utilizes many of these same principles but does so in a unified manner in order to maximize the efficiency of transportation facilities during all periods of the day and under both recurrent and nonrecurrent congestion conditions. ATM typically relies on comprehensive automated systems to continuously monitor and adjust roadway management strategies as traffic conditions change over time. This approach stresses automation, which in turn, allows for dynamic deployment of strategies to quickly optimize performance and enhance throughput and safety. Through continuous system monitoring, dynamic response, and coordination of systems, ATM provides a holistic approach to transportation system management (Sisiopiku et al., 2009).

\section{Advanced traffic management options}

ATM is composed of a set of different strategies that can work synergistically (or on an individual basis) to achieve the common goal of congestion alleviation. Strategies 
considered under the ATM umbrella include: speed harmonization, high occupancy vehicle lanes, dynamic junction control, and temporary shoulder use. Details on the principles of each of these options are provided below.

\subsection{Speed harmonization}

Speed harmonization systems use changeable speed limit signs posted over each lane to regulate freeway speeds based on prevailing traffic conditions. Speed limits can be adjusted when freeway conditions are unsuitable for high speed operations, such as under adverse weather conditions or low visibility. Speed limits can also be lowered when there is an incident or congestion on specific segments in order to reduce the chances of secondary accidents and facilitate a smoother flow of traffic.

Advanced versions of the speed harmonization strategy include dynamic implementation (based on real-time travel demand, not simply time of day) along with dynamic speed controls to improve the overall safety and efficiency of freeway operations. Through speed harmonization, agencies can make the most of existing capacity by delaying the point at which flow breaks down and stop-and-go conditions occur.

\subsection{High Occupancy Vehicle (HOV) lanes}

HOV lanes are lanes available to vehicles that meet a minimum occupancy requirement. The main purpose of $\mathrm{HOV}$ facilities is to maximize the passenger-carrying capacity of the roadway, especially in peak periods. Entrance restrictions typically apply to passenger vehicles carrying less than two persons. The use of HOV lanes by transit buses, vanpools, and carpools is encouraged to further increase the carrying capacity of HOV lanes and lighten the traffic load of adjacent general use lanes.

The main objective of HOV use is to reduce congestion and encourage people to carpool or vanpool. This behavior reduces air pollution and saves money (NCDOT, 2008). HOV lanes can be open 24 hours a day, 7 days a week, or managed dynamically, in which case they become part of ATM.

Often HOV lanes are utilized as High Occupancy Toll Lanes (HOT), allowing singleoccupant vehicles to use HOV lanes during peak hours in return for a toll. Under the value priced management option, the tolls can change dynamically according to real-time traffic conditions and manage the maximum number of cars in the HOT lanes in order to keep the traffic lanes free of congestion, even during rush hour. Examples of states with proven applications of HOT lanes include California, Colorado, Florida, Minnesota, Texas, Utah, and Washington.

\subsection{Junction control}

The junction control strategy is a combination of ramp metering and lane control at onramps (Berman et al., 2006). Typically, junction control is applied at entrance ramps or at merge points where the number of downstream lanes is fewer than that of upstream lanes. In the U.S., this strategy has been applied statically by dropping one lane from the 
outside lanes or merging the two inside lanes (Tignor et al., 1999). In Germany and other European countries this is done dynamically by installing lane control signals over both upstream approaches before the merge. This strategy gives priority to the facility with the higher volume and results in a lane drop on the approach with the lower volume (Mirshahiet et al., 2007).

The objective of junction control through either static or real-time means is the better management of recurrent congestion by making traffic flow more uniform, utilizing more effectively the existing roadway capacity, and improving traffic safety. The literature reports decreases in primary collisions by 15 to 25 percent through implementation of junction control strategies (Stone et al., 2007).

\subsection{Temporary shoulder lane use}

Temporary use of shoulder lanes as travel lanes began in many cities in the late 1960s. This strategy is usually employed during peak periods and in the peak direction and gives permission to vehicles to use either the right or left shoulder lanes in specific conditions. Temporary shoulder lane provides additional lane(s) within the existing pavement, without the need to widen the freeway (FHWA, 2003). Under the ATM concept, the use of shoulder lanes is done by using dynamically variable signs to let drivers know that the shoulder lane is open in a certain segment. The purpose of temporary shoulder use is to improve the performance of freeway facility by providing additional capacity when needed.

Temporary use of shoulder lanes on freeways is a strategy currently employed in select U.S. cities to provide a temporary capacity increase for congested freeways during the times when demand is greatest. In a typical application, motorists are allowed to use shoulders as an extra driving lane during the AM and PM peak periods while in other deployments, freeway shoulder lanes are used by transit buses during certain periods of the day.

Temporary use of shoulder lanes is also employed as an active congestion management strategy in Europe. In several countries, it is coupled with speed harmonization to enhance its effectiveness. Speed harmonization systems allow freeway operators to reduce freeway speeds during times of shoulder lane usage to ensure that improved traffic operations are also coupled with reduction in the chance of occurrence and severity of crashes.

The use of the shoulder lanes requires the presence of traffic control devices in order to inform the users whether the shoulder lane is open or not. A variety of traffic control devices and other pertinent technologies should be utilized to ensure driver safety when opening the shoulder lane. These include lane control signals, dynamic speed limit signals, dynamic message signs, closed-circuit television cameras, roadway sensors, and emergency roadside telephones (Mirshahiet et al., 2007). An example of a system in operation utilizing several of the above mentioned technologies is depicted in Figure 1. 


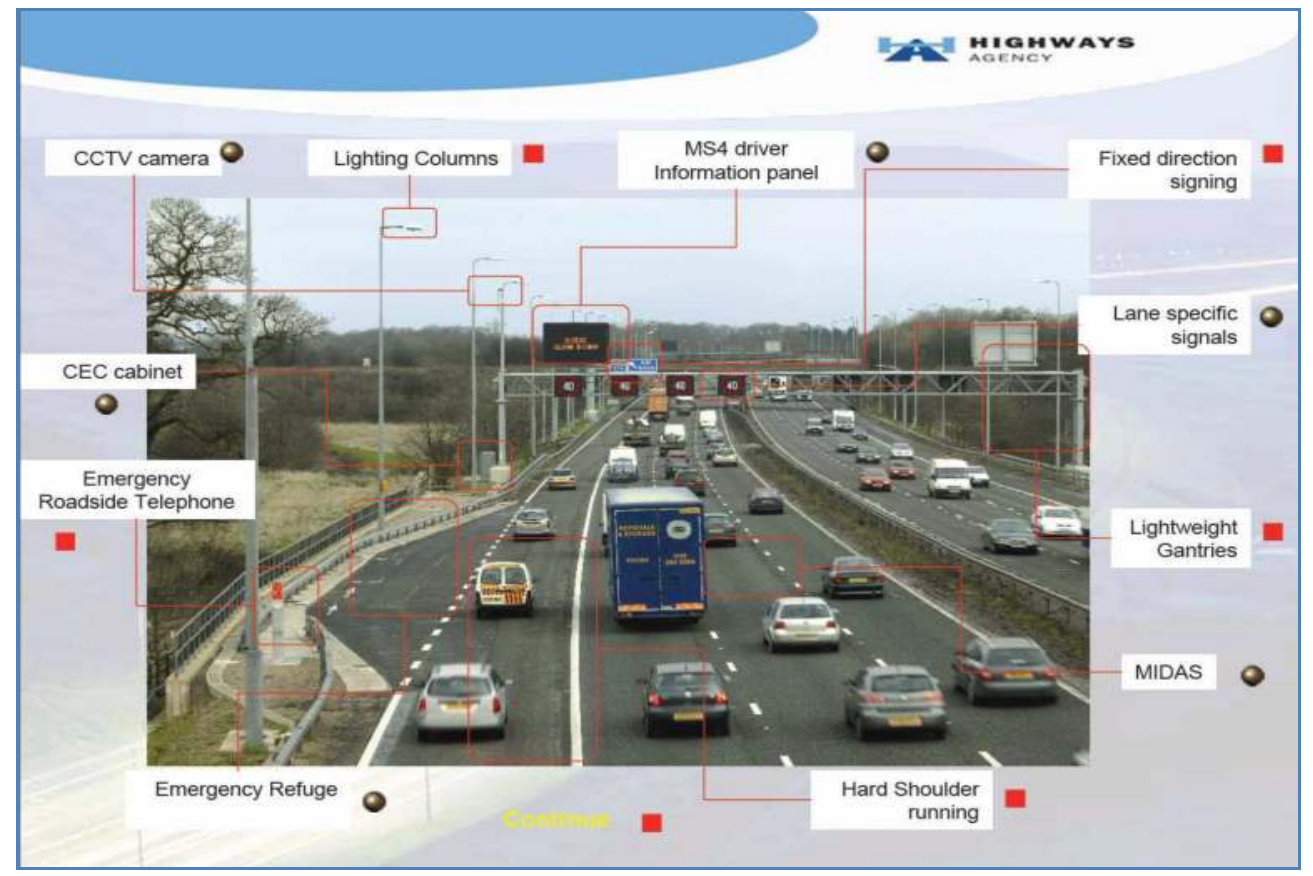

Fig. 1. Traffic Devices and Strategies in M24 UK (Stone et al., 2007).

\subsection{Expected ATM benefits}

European studies from Denmark, England, Germany, and the Netherlands confirm that ATM strategies result in great benefits, including increase in vehicle throughput, crash reduction, improvement in trip reliability, decrease in congestion and traffic delays, and an overall improvement in the driving experience. Depending on the location and the combination of strategies deployed, specific benefits measured in Europe as a result of this congestion management approach include the following (Mirshahiet et al., 2007):

- Increase in average throughput for congested periods of 3 to $7 \%$

- Increase in overall capacity of $3 \%$ to $22 \%$.

- Decrease in primary incidents of $3 \%$ to $30 \%$.

- Decrease in secondary incidents of $40 \%$ to $50 \%$.

- Overall harmonization of speeds during congested periods.

- Decreased headways and more uniform driver behavior.

- Increase in trip reliability, and

- Ability to delay the onset of freeway breakdown.

Based on international experience, a summary of potential benefits from deployment of a variety of ATM options in the U.S. is provided in Table 1. 


\begin{tabular}{|c|c|c|c|c|c|c|c|c|c|c|c|c|c|}
\hline \multirow[b]{2}{*}{$\begin{array}{l}\text { Active Traffic } \\
\text { Management } \\
\text { Strategy }\end{array}$} & \multicolumn{13}{|c|}{ Potential Benefits } \\
\hline & 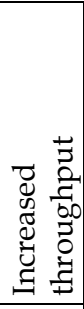 & 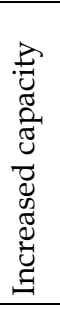 & 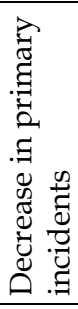 & 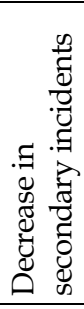 & 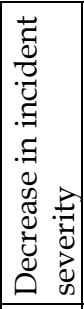 & 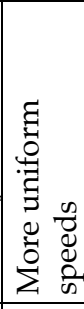 & 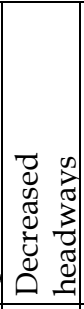 & 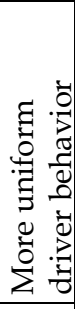 & 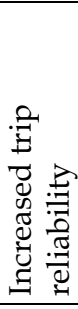 & 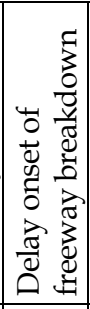 & 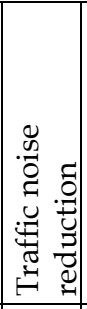 & 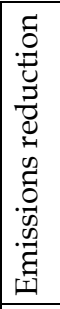 & 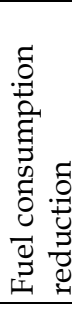 \\
\hline $\begin{array}{l}\text { Speed } \\
\text { harmonization }\end{array}$ & $\mathrm{X}$ & & $X$ & & $X$ & $X$ & $X$ & $X$ & $X$ & $X$ & $X$ & $X$ & $x$ \\
\hline $\begin{array}{l}\text { Temporary } \\
\text { shoulder use }\end{array}$ & $X$ & $X$ & & & & & & & $X$ & $X$ & & & \\
\hline $\begin{array}{l}\text { Queue } \\
\text { warning }\end{array}$ & & & $X$ & $X$ & $X$ & $X$ & $X$ & $X$ & $X$ & & $X$ & $X$ & $X$ \\
\hline $\begin{array}{l}\text { Dynamic } \\
\text { merge control }\end{array}$ & $X$ & $X$ & $X$ & & & $X$ & & $X$ & $X$ & $X$ & $X$ & $X$ & $X$ \\
\hline $\begin{array}{l}\text { Construction } \\
\text { site } \\
\text { management }\end{array}$ & $X$ & $X$ & & & & & & & $X$ & & $X$ & $X$ & $X$ \\
\hline $\begin{array}{l}\text { Dynamic } \\
\text { truck } \\
\text { restrictions }\end{array}$ & $X$ & $X$ & & & & $X$ & & $X$ & $X$ & & & $\mathrm{X}$ & $X$ \\
\hline $\begin{array}{l}\text { Dynamic } \\
\text { rerouting \& } \\
\text { traveler info }\end{array}$ & $X$ & & $X$ & $X$ & & & & $X$ & $X$ & & & $\mathrm{X}$ & $X$ \\
\hline $\begin{array}{l}\text { Dynamic lane } \\
\text { markings }\end{array}$ & $X$ & $X$ & & & & & & & $X$ & & & & \\
\hline $\begin{array}{l}\text { Automated } \\
\text { speed } \\
\text { enforcement }\end{array}$ & & & $X$ & & $x$ & $x$ & & $X$ & $X$ & & & $X$ & $X$ \\
\hline
\end{tabular}

Table 1. Potential Benefits from ATM Implementation (Mirshahiet et al., 2007).

\section{Advanced traffic management in the United States}

\subsection{Current state of practice}

ATM received attention in the U.S. only in the recent years as an approach with great potential to address the ever-growing congestion problems in urban areas. A milestone in the development of ATM in the U.S. was the 2006 International Technology Scanning Program sponsored by the FHWA, the American Association of State Highway and Transportation Officials (AASHTO), and the National Cooperative Highway Research Program (NCHRP). Through this effort, a team of U.S. experts studied European ATM systems and concluded that ATM is the next evolution in congestion management in the U.S. In their report to FHWA, the 
experts identified nine key recommendations related to congestion management with a potential to ease congestion in the U.S., as follows (Mirshahiet et al., 2007):

- Promote ATM to optimize existing infrastructure during recurrent and non-recurrent congestion.

- Emphasize customer orientation and focus on trip reliability.

- Integrate active management into infrastructure planning and programming processes.

- Make operations a priority in planning, programming, and funding processes.

- Develop tools to support active management investment decisions.

- Consider public-private partnerships and innovative financing and delivery strategies.

- $\quad$ Provide consistent messages to roadway users.

- Consider pricing as only one component of a total management package, and

- Include managed lanes as part of the overall management of congested facilities.

A 2009 exploratory study by Sisiopiku et al. surveyed system managers from several state transportation agencies to identify current and planned ATM initiatives in the U.S. The study focused on four state agencies that had either implemented or were in the process of implementing ATM projects in their highways systems, namely Washington State DOT (WSDOT), Minnesota DOT (MnDOT), Virginia DOT (VDOT), and California DOT (CalTrans). A summary of ATM initiatives in each of these states as reported in Sisiopiku et al. $(2009 \mathrm{~b})$ and updated to reflect recent developments follows.

\subsubsection{Washington State DOT (WSDOT)}

The Washington State DOT has two ATM projects recently completed: the SR 520/I-90 ATM Project and the I-5 Variable Speed Safety Project. The SR 520/I-90 project installed variable speed signs and lane control signals on the SR 520 and I-90 bridges over Lake Washington in Seattle. The goal was to improve speed control and better cope with incidents during the reconstruction of the SR 520 floating bridge. The I-5 project installed variable speed limit and lane control signs on the northbound lanes of I-5 approaching Seattle. This is a speed harmonization system that automatically adjusts speed limits based on prevailing traffic conditions to optimize throughput and safety and is operational since 2010.

The WSDOT is treating these two projects as the beginning of a broader ATM program and the outcomes are closely monitored. At present, funding is seen as one of the major obstacles to the expansion of this program. It should be noted that these ATM projects had unique funding sources: the I-5 project was funded as part of a mitigation plan for the reconstruction of the downtown Seattle viaduct. As yet there is no specific funding for additional ATM efforts.

The costs for each program are averaging about $\$ 4.0$ million per mile, with lane control sign structures located approximately every $1 / 2$ mile. WSDOT staff did not identify any substantial implementation issues with either project, although because both are the first of their kind in the state they are being monitored very closely.

\subsubsection{Minnesota DOT (MnDOT)}

The Minnesota DOT has more than one major ATM projects in operation. The I-35W project took place in 2009 in an effort to convert/construct HOT lanes on a 14-mile segment of I35W near Minneapolis. Part of this effort required the implementation of a shoulder lane use 
program on the last two mile segment into Minneapolis. The shoulder lanes are used only during peak hours and require a toll, which can be varied based on prevailing traffic conditions. Overhead lane control signings are placed approximately every half mile and speed advisories are conveyed via standard CMS message signs.

The MnDOT obtained legislative approval to implement a shoulder use program for I-35W. This was the first shoulder lane use program in the state for passenger vehicles, although MnDOT has already implemented extensive shoulder use programs for transit vehicles. The experience with transit shoulder use has been excellent and helped with public education about the project, since motorists were already familiar with shoulder use during peak periods. The program was funded under an FHWA urban partnership agreement and is monitored extensively in an effort to assess the feasibility of future similar projects.

Moreover, variable speed limits are available since 2010 on I-35W between Bloomington and Burnsville. They are part of a real-time system called Smart Lanes, which is expected to expand on I-94 between St. Paul and Minneapolis by fall 2011.

\subsubsection{Virginia DOT (VDOT)}

The Virginia DOT has several ATM projects either in operation or in the planning stages located in the Northern Virginia/Washington, D.C. area. They include the use of shoulder lanes, variable speed limits, and the construction of HOT lanes in the I-459 corridor.

VDOT has a shoulder lane use program in operation in the I-66 corridor. Historically the shoulder lanes have been used only during strictly defined AM and PM peak periods, regardless of traffic conditions, and only in the peak direction. Recently, however, VDOT has extended the use of shoulder lanes to 5:30 - 11:00 in the morning and 2:00 - 8:00 in the afternoon to handle growing traffic congestion. More importantly, VDOT has also begun to allow shoulder lane use during major incidents or when construction causes lanes to be closed. This has effectively made the shoulder use program an ATM strategy.

Furthermore, VDOT uses variable speed limits (VSL) as part of the Woodrow Wilson Bridge project on 195/495. The variable speed limit signs have been used primarily to reduce vehicle speeds, improve traffic flow, and improve safety during periods of construction. The system is active in a 7 mile long segment of the I-95/495 corridor just west of the Wilson Bridge. The system has been successful enough that in May of 2009 VDOT decided to extend the use of the VSL system to the AM and PM peak periods, when it functions as a speed harmonization system. VDOT is currently collecting data on its effectiveness.

Another ATM initiative is the construction of HOT lanes on I-459 and I-95. While traditional HOV-3 vehicles and motorcycles will be able to use the lanes for free, non-HOV vehicles will be allowed to pay to use the lanes. Lane usage fees will vary depending on demand and road conditions. Project construction has begun but operation is not anticipated until 2013.

Discussions with VDOT staff indicated a commitment to implement ATM strategies. The major obstacle to implementation is seen as funding. ATM measures require extensive infrastructure for surveillance and traffic control; implementation of ATM strategies can prove quite costly and funding is not available for a larger program at this point. Nonetheless, reactions to initial projects have been positive.

Implementation issues to this point have been seen as manageable. VDOT has monitored traffic operations in the I-66 corridor to ensure that the use of shoulder lanes has not 
reduced safety. To date their experience has been similar to that of other agencies that have implemented shoulder lane programs, which have found minimal impacts to safety. VDOT staff indicated that new ATM programs will be monitored extensively to ensure that they are producing cost effective results.

\subsubsection{California DOT (CalTrans)}

In 2009, CalTrans was contacted to assess the status of ATM in the state. CalTrans staff said that there were no ATM projects active within the state, although the first was in the planning stages for Alameda County and the Bay Area. The I-80 Integrated Corridor Mobility (ICM) Project aims at incorporating several ATM strategies, namely adaptive ramp metering, variable speed limits (speed harmonization), and adaptive lane controls. These strategies would be combined to regulate the flow of traffic in the I- 80 corridor in order to maximize throughput, minimize incidents, and better handle incidents when they occur.

CalTrans staff said there were no long term ATM plans beyond the current I- 80 project and that the state's current financial problems are a limiting factor in that regard. Staff did indicate, however, that they felt ATM would become more important in state planning in the future. One of the primary areas of focus for managing congestion in the future will be $\mathrm{HOV} / \mathrm{HOT}$ lanes and those will likely require extensive shoulder use programs to be feasible. CalTrans staff indicated that ATM would have to be an integral part of such programs. Staff also indicated that the State has interest in testing speed harmonization in the future, although there are no firm plans in the works.

Overall, the interviews with state agencies indicated that there is interest in implementing ATM strategies in the US in the future but the initial deployments would be limited. The primary implementation issues identified were a. funding, b. legal, and c. public education (Sisiopiku et al., 2009).

All state representatives interviewed said that available funding was a limiting factor in their decisions to develop ATM programs. Only a few projects have been initiated and most of the ones that are have unique funding sources (e.g., they are mitigation measures tied to a larger highway project). The infrastructure required for ATM strategies can be extensive so funding is an ongoing concern.

Although all agencies interviewed were able to obtain the legal and legislative clearances needed, some ATM strategies, such as shoulder lane use, raise questions about public safety and need to be addressed at a local level.

Efforts to educate the public about the proper use of ATM options are required, because many of the strategies are new to this country. VDOT, for example, has developed a public education campaign for the variable speed limit system at the I-459 Wilson Bridge Project. The campaign includes advertisements and a website explaining the purpose and function of the system. Because so few ATM projects have been implemented, an assessment of the best public education strategies would prove useful.

In general, the states interviewed did not see major technical hurdles to implementing ATM strategies. The technology, for the most part, was viewed as having been proven either in isolated ITS applications or in European ATM applications. The most likely initial applications of ATM technologies include shoulder lane use, speed harmonization, dynamic HOT lanes, and adaptive lane controls. 


\subsection{The future of ATM in the U.S.}

Planning for ATM is an important ingredient for success. Whether or not to implement ATM and its operational strategies is a policy decision that must be made at the appropriate governing level. To that end, policymakers should develop both short- and long-range plans that incorporate ATM into the framework of transportation alternatives. Furthermore, agencies should approach ATM proactively by including it in current and future plans for target corridors. They should assess what ATM capabilities already exist in those corridors and what components need to be added to facilitate active management, even if conditions do not currently warrant such operational strategies. This forward-thinking approach will ensure that the infrastructure is put into place during future projects so that ATM can be implemented when warranted by congestion levels and mobility needs. In some regions, legislative support may be necessary to make this operational approach possible (Mirshahiet et al., 2007).

The technologies required for implementation are currently available in the market; however, research and development may be required to refine existing systems, and careful selection of available technologies should take place to improve cost/effectiveness while accounting for local needs and special conditions.

Implementation, operation, maintenance, enforcement, and marketing are some of the policy decisions that govern a successful ATM system. For example, potential policy decisions that would need to be made in tandem with the planning and implementation of temporary shoulder lane use are being reviewed and documented. Special emphasis should be placed on the development of a set of procedures that will clearly describe how to open and close the shoulder to traffic operation, and assign roles and responsibilities. Moreover, considerations related to maintenance, compliance, and enforcement, and institutional issues (such as regulatory and legal issues, finance, organization and management issues, and human resources) must be studied carefully (FHWA, 1994).

Another key consideration is the availability of funding. Therefore, funding resources at the federal, state, or local level that can potentially support design, implementation, operation, maintenance, and marketing of the project should be identified and committed.

In addition, various institutional issues are essential to the successful implementation of ATM and include customer orientation; the priority of operations in planning, programming, and funding processes; cost-effective investment decisions; public-private partnerships; and a desire for consistency across borders. These issues need to be considered carefully prior to implementation in order to maximize the potential for success.

\subsection{Promising ATM options for deployment in the U.S.}

The FHWA International Scan Tour Report (Mirshahiet et al., 2007) offered specific recommendations for ATM implementation in the U.S. in response to congestion. A summary of these recommendations follows.

\subsubsection{Speed harmonization}

The United States should implement speed harmonization on freeways as a strategy to actively manage the network and delay the onset of congestion under normal operating conditions. The system should include the following elements (Mirshahiet et al., 2007): 
- Sufficient sensor deployment for traffic and weather monitoring to support the strategy.

- Adequate installation of sign gantries to ensure that at least one speed limit sign is in sight at all times.

- $\quad$ Placement of speed limit signs over each travel lane.

- An expert system that deploys the strategy based on prevailing roadway conditions without requiring operator intervention. It is critical that this expert system be reliable and accurate to gain the trust and acceptance of the public.

- Connection to a traffic management center that serves as the focal point for the system.

- Passage of enabling legislation and related laws to allow for dynamic speed limits.

- Uniform signing related to speed harmonization and its components.

- Modeling tools to assess the impacts of speed harmonization on overall network operations.

- Closed-circuit television (CCTV) cameras to support the monitoring of the system.

- Dynamic message signs to provide traveler information and regulatory signs as appropriate, and

- Automated speed enforcement to deter violations.

\subsubsection{Temporary shoulder lane use}

Temporary shoulder lane use should be implemented, where appropriate, to temporarily increase capacity during peak travel periods. Specific elements of the operational strategy should include the following (Mirshahiet et al., 2007):

- Deployment in conjunction with speed harmonization.

- Passage of enabling legislation and related laws to allow the shoulder to be used as a travel lane.

- A policy for uniform application of the strategy through entrance and exit ramps and at interchanges.

- Adequate installation of sign gantries to provide operational information and to ensure that they are in sight at all times.

- Placement of lane control signals over each travel lane.

- Uniform signing and markings related to temporary shoulder use.

- CCTV cameras with sufficient coverage to verify the clearance of the shoulder before deployment.

- Provision of pullouts at regular intervals with automatic vehicle detection to provide refuge areas for minor incidents.

- $\quad$ Provision of roadside emergency call boxes at emergency pullouts.

- Special lighting to enhance visibility of the shoulder.

- Advanced incident detection capabilities.

- Comprehensive incident management program.

- Connection to a traffic management center that serves as the focal point, and

- Dynamic message signs to provide guide sign information and regulatory signs to adapt to the addition of the shoulder as a travel lane.

\subsubsection{Queue warning}

Queue warning message displays should be implemented at regular intervals to warn of the presence of upstream queues based on dynamic traffic detection. Specific elements of the operational strategy should include the following (Mirshahiet et al., 2007): 
- Deployment in conjunction with speed harmonization.

- Sufficient sensor deployment for traffic monitoring to support the strategy.

- Adequate installation of sign gantries to ensure that at least one queue warning sign is in sight at all times.

- An expert system that deploys the strategy based on prevailing roadway conditions without requiring operator intervention. It is critical that this expert system be reliable and accurate to gain the trust and acceptance of the public.

- Uniform signing to indicate congestion ahead, and

- Connection to a traffic management center that serves as the focal point for the system.

\subsubsection{Dynamic merge control}

At merging points from major interchange ramps, consideration should be given to dynamically metering or closing specific upstream lanes, depending on traffic demand. This could incorporate existing ramp metering systems and offer the potential of delaying the onset of main lane congestion and balancing demands between upstream roadways. Specific elements of the operational strategy should include the following (Mirshahiet et al., 2007):

- An expert system that deploys the strategy based on prevailing roadway conditions without requiring operator intervention. It is critical that this expert system be reliable and accurate to gain the trust and acceptance of the public.

- CCTV cameras to support the monitoring of the system.

- Installation of lane control signals over the main lanes and the ramp lanes with a signal over each travel lane.

- Adequate installation of sign gantries upstream of the deployment to ensure sufficient advance warning is provided to roadway users through the use of dynamic message signs.

- Adequate installation of sign gantries with dynamic message signs upstream of the deployment to provide guide sign information and regulatory signs to adapt to the changes in lane use.

- Uniform signing to indicate merge control is in use.

- Automated enforcement to deter violations.

- A bypass lane for emergency vehicles, transit, or other identified exempt users, and

- Connection to a traffic management center that serves as the system's focal point.

\section{Birmingham case study}

\subsection{Methodology}

Drawing from the European experience and with input from the few available U.S. studies, a study procedure was developed and implemented in order to assess the feasibility of temporary shoulder lane use as a strategy to reduce congestion in the Birmingham region. This included:

- Identification of candidate corridors and preliminary assessment of implementation potential.

- Quantitative evaluation of operational impacts from implementation, and

- Estimation of benefits and costs. 
Preliminary assessment of temporary shoulder lane implementation along candidate corridors considered traffic demand, level of service (LOS), physical characteristics and geometric restrictions. The assessment led to the selection of a segment of I-65 traversing through the city of Birmingham as a high-priority corridor for further analysis. I-65 is a major North-South interstate freeway that extends from Gary, IN on the north to Mobile, AL on the south.

Simulation modeling was undertaken to analyze the impacts of a temporary shoulder lane use system on a subsection of the I-65 corridor extending from I-459 to University Blvd, which corresponds to the portion of the study corridor near Birmingham that experiences the worst Level-of-Service (LOS). The microscopic simulation model CORSIM was used to perform the analysis.

CORSIM is one of the tools available within TSIS, a suite of simulation models developed by FHWA and used extensively by transportation agencies and practitioners in the U.S. and abroad for over three decades. The CORSIM simulator in TSIS can simulate traffic operations on integrated networks containing freeway and surface streets. The model has the ability to simulate fairly complex geometric conditions and realistic driver behavior after it is appropriately calibrated and validated. Moreover, the model offers the capability to analyze a variety of lane management strategies, a feature of importance for this case study (Sisiopiku \& Cavusoglu, 2008).

The Birmingham case study considered the potential use of a shoulder lane in response to both recurring and non-recurring congestion. Key measures of effectiveness (MOEs) and resulting improvements in operational efficiency were obtained for several scenarios and used to assess operational impacts and determine the feasibility of implementation of the proposed strategy.

Quantification of expected benefits and costs from deployment of temporary shoulder lanes along the I-65 corridor in Birmingham was also performed to estimate economic impacts from possible deployment and determine the most economically efficient investment alternative.

The cost-benefit analysis considered life-cycle costs and life-cycle benefits of the project alternatives under study. The life-cycle costs include engineering, construction, and maintenance. Life-cycle benefits include savings in vehicle operation and travel time, safety, and emission reduction. Following the analysis, the costs and benefits were discounted on year-to-year basis and projected for the analysis period 2010 to 2020. A description of the study site characteristics and the scenarios tested follows.

\subsection{Study site characteristics}

The site chosen to examine the implementation of temporary shoulder lane usage in this research is the northbound I-65 from the junction with I-459 to the University Blvd junction. The geometric characteristics of the selected segment are summarized in Table 2.

According to the Mobility Matters Project in Birmingham, the 2005 average daily traffic volumes along the study segment ranged from 111,000 and 146,000 vehicles per day (vpd). This number is expected to reach 179,000 and 221,000 vpd by 2030 (PBS\&J, 2009). 


\begin{tabular}{|l|c|c|c|c|}
\hline \multirow{2}{*}{ Segment } & Number & Lane Width & \multicolumn{2}{c|}{ Shoulder Lane Width (ft) } \\
\cline { 4 - 5 } & of Lanes & $(\mathrm{ft})$ & Left & Right \\
\hline I-459 to US 31 & 4 & 12.0 & 9.5 & 12.5 \\
\hline US 31 to Alford Ave & 3 & 12.0 & 12.0 & 12.5 \\
\hline Alford Ave to Lakeshore Dr & 3 & 12.0 & 20.0 & 12.0 \\
\hline Lakeshore Dr to Oxmoor Rd & 3 & 11.5 & 7.0 & 12.0 \\
\hline Oxmoor Rd to Green Springs & 3 & 12.0 & 13.0 & 8.0 \\
\hline Green Springs to University Ave & 3 & 12.0 & 10.0 & 11.5 \\
\hline
\end{tabular}

Table 2. Geometric Characteristics of Study Corridor.

Based on the hourly traffic volumes collected by by the Alabama Department of Transportation (ALDOT) along the I-65, the morning peak hour (which affects primarily the northbound direction) is more critical than the evening peak hour that primarily affects southbound traffic, and thus was selected for further analysis (Sisiopiku et al., 2009).

\subsection{Alternatives analysis}

Study scenarios were developed and tested with the TSIS simulation model for a period of four hours (5:30 AM to 9:30 AM), including the morning peak hour (6:30 AM to 8:30 AM). The scenarios aimed at examining traffic operations along the study corridor with and without the use of temporary shoulder lanes under normal and incident traffic conditions. More specifically, four scenarios were developed assuming non-incident (normal) traffic conditions to examine the efficiency of using temporary shoulder lanes to ease recurrent traffic congestion on the northbound I-65 corridor. In all four scenarios, the free flow speed was set to $60 \mathrm{mph}$.

Scenario 1 served as a baseline for comparisons and assumed that the network operates under normal conditions without the use of the shoulder lanes.

Scenario 2 simulated the network with the utilization of the left shoulder as an additional lane from U.S. 31 to the end of the network. The shoulder lane was open during the entire simulation period and represented the case of an added lane.

Scenario 3 was similar to the second study scenario, however, the temporary shoulder lane was available for use only in the morning peak hour (between 6:30 AM and 8:30 AM). This scenario serves as a typical example of an ATM application where the temporary shoulder lane is used in response to congestion.

Scenario 4 simulated the network under normal conditions while opening a small portion (i.e., 600 feet) of the right shoulder upstream of three study exits, namely Alford Ave (Exit 254), Lakeshore Pkwy (Exit 255), and Oxmoor Rd (Exit 256) for the total simulation time. This scenario tested the possibility of using the right shoulder as an additional exit lane in order to minimize the potential impact that long queues of exiting vehicles may have on traffic operations along the mainline.

Moreover, three scenarios were developed to examine the efficiency of using temporary shoulder lanes under incident conditions. For practical purposes these were numbered consequently as Scenarios 5 through 7. All incident scenarios assumed that an incident occurred blocking the right lane of link $(564,565)$ for $1 \mathrm{hr}$ (i.e., from 6:30 AM to 7:30 AM). The incident site was located roughly in the middle section of the study network. 
Scenario 5 considered the presence of the incident and assumed that no actions were taken. This scenario serves as the incident case base line for comparison purposes (i.e., do-nothing approach).

Scenario 6 simulated the network with the incident presence but assumed that vehicles were allowed to ride on the left shoulder lane downstream of the incident for one hour $(6: 30$ $\mathrm{AM}$ to 7:30 $\mathrm{AM}$ ) to minimize the impact of the incident on traffic operations.

The last scenario considered (Scenario 7) is similar to Scenario 6, except for the fact that the left shoulder lane downstream of the incident is open for use for 2 hours i.e., from 6:30 AM to 8:30 $\mathrm{AM}$, to further expedite the clearance of the incident and return to normal operations. Table 3 provides a summary of scenarios considered in the Birmingham case study.

\subsection{Results}

\subsubsection{Operational analysis results}

The results presented in Table 4 are for the entire study corridor (i.e., network wide statistics) for the seven scenarios considered in the study. MOEs considered include the total travel time (hours), the total delay time (hours), the average travel speed (mile/hour), the delay time (hours), and the total time (hours). Analysis and interpretation of the results under normal - and incident conditions follows.

\begin{tabular}{|c|c|c|c|c|}
\hline Scenarios & Description & $\begin{array}{l}\text { Available } \\
\text { lanes }\end{array}$ & $\begin{array}{l}\text { Left shoulder lane } \\
\text { in use (Duration) }\end{array}$ & $\begin{array}{c}\text { Right } \\
\text { shoulder lane } \\
\text { in use } \\
\text { (Duration) }\end{array}$ \\
\hline \multicolumn{5}{|c|}{ Normal Traffic Conditions } \\
\hline 1 & No shoulder use & 3 & $\begin{array}{l}0 \text { (5:30 AM to } \\
9: 30 \text { AM) }\end{array}$ & $\begin{array}{l}0 \text { (5:30 AM to } \\
9: 30 \text { AM) }\end{array}$ \\
\hline 2 & $\begin{array}{c}\text { Continuous left shoulder } \\
\text { lane use }\end{array}$ & 3 & $\begin{array}{c}1 \text { (5:30 AM to } \\
9: 30 \mathrm{AM}) \\
\end{array}$ & $\begin{array}{c}0 \text { (5:30 AM to } \\
9: 30 \mathrm{AM})\end{array}$ \\
\hline 3 & $\begin{array}{l}\text { Continuous left temporary } \\
\text { shoulder lane use }\end{array}$ & 3 & $\begin{array}{c}1 \text { (6:30 AM to } \\
8: 30 \text { AM) }\end{array}$ & $\begin{array}{l}0 \text { (5:30 AM to } \\
9: 30 \mathrm{AM})\end{array}$ \\
\hline 4 & $\begin{array}{l}\text { Right shoulder lane use at } \\
\text { exits }\end{array}$ & 3 & $\begin{array}{c}0 \text { (5:30 AM to } \\
9: 30 \mathrm{AM})\end{array}$ & $\begin{array}{c}1 \text { (5:30 AM to } \\
9: 30 \mathrm{AM})\end{array}$ \\
\hline \multicolumn{5}{|c|}{ Incident Conditions } \\
\hline 5 & No shoulder use & 3 or 2 & $\begin{array}{l}0 \text { (5:30 AM to } \\
9: 30 \text { AM) }\end{array}$ & \\
\hline 6 & $\begin{array}{l}\text { Continuous left temporary } \\
\text { shoulder lane use down- } \\
\text { stream of the incident }\end{array}$ & 3 or 2 & $\begin{array}{l}1 \text { (6:30 AM to } \\
\text { 7:30 AM) }\end{array}$ & \\
\hline 7 & $\begin{array}{l}\text { Continuous left temporary } \\
\text { shoulder lane use } \\
\text { downstream the incident }\end{array}$ & 3 or 2 & $\begin{array}{l}1 \text { (6:30 AM to } \\
8: 30 \mathrm{AM})\end{array}$ & \\
\hline
\end{tabular}

Table 3. Summary of Case Study Scenarios. 


\begin{tabular}{|c|c|c|c|c|c|c|c|}
\hline Scenario & 1 & 2 & 3 & 4 & 5 & 6 & 7 \\
\hline $\begin{array}{c}\text { Shoulder } \\
\text { Lane Use }\end{array}$ & No & Left & Left; Peak only & Right; 3 exits & No & Left; 1 hr & Left; 2 hrs \\
\hline $\begin{array}{c}\text { Total Travel } \\
\text { Time (hrs) }\end{array}$ & 6,790 & 3,963 & 4,478 & 6,523 & 7,872 & 6,758 & 5,498 \\
\hline $\begin{array}{c}\text { Total Delay } \\
\text { Time (hrs) }\end{array}$ & 3,394 & 446 & 991 & 3,127 & 4,598 & 3,337 & 1,963 \\
\hline $\begin{array}{c}\text { Avg. Travel } \\
\text { Speed (mph) }\end{array}$ & 29.90 & 53.10 & 46.60 & 31.30 & 25.10 & 30.30 & 38.70 \\
\hline $\begin{array}{c}\text { Delay Time } \\
\text { (min/mile) }\end{array}$ & 1.01 & 0.13 & 0.28 & 0.92 & 1.42 & 0.98 & 0.57 \\
\hline $\begin{array}{c}\text { Total Time } \\
\text { (min/mile) }\end{array}$ & 2.01 & 1.13 & 1.29 & 1.93 & 2.43 & 1.99 & 1.57 \\
\hline
\end{tabular}

Table 4. Network-Wide Results for All Scenarios; Birmingham, AL Case Study.

\section{Scenarios with normal traffic conditions}

According to the findings in Table 4, the use of the left shoulder lane in Scenarios 2 and 3 results in considerable savings in travel time and delays, as compared to the baseline (Scenario 1). As expected, the continuous availability of an extra lane (Scenario 2) results in the largest improvements, slashing total time by $42 \%$ (from 6,790 hrs in Scenario 1 to 3,963 hrs in Scenario 2).

The temporary use of the NB shoulder lane for 2 hrs during the morning peak (Scenario 3) still shows a significant improvement over current conditions resulting in a reduction in the total network travel time by $34 \%$ and delay by $71 \%$ when compared to the baseline (Scenario 1). Similar gains are observed in average speed where the $29.9 \mathrm{mph}$ average network speed observed under regular conditions (Scenario 1) increases by 56\% (to $46.6 \mathrm{mph}$ ) under the ATM operations, i.e., when the left shoulder lane is open during the peak hour from 6:30 AM to 8:30 AM.

The results clearly indicate the excellent potential of temporary shoulder lane use as an ATM tool for addressing recurrent congestion along I-65. On the other hand, the use of the right northbound shoulder lane upstream of three exit locations (Scenario 4) shows only a small positive impact and results in a small reduction in the total network travel (4\%) time and delay (9\%) over Scenario 1. A slight increase (5\%) in average speed was also noticed (from $29.9 \mathrm{mph}$ to $31.3 \mathrm{mph}$ ) in this case.

When comparing the two temporary shoulder lane options, i.e., continuous left lane shoulder versus right shoulder near exits, the former is clearly a winner, as the anticipated 
benefits clearly overshadow those expected from its short length, temporary, right shoulder use counterpart.

\section{Scenarios with incident conditions}

As anticipated, an incident blocking one general purpose traffic lane for $1 \mathrm{hr}$ (Scenario 5) further degraded the overall performance of the study network. Compared to non-incident conditions (Scenario 1), the do-nothing approach under incident conditions resulted in a decrease in average speed of $16 \%$ (from $29.9 \mathrm{mph}$ to $25.1 \mathrm{mph}$ ) and average delay time increase of $41 \%$ (from $1.01 \mathrm{~min} / \mathrm{mile}$ to $1.42 \mathrm{~min} / \mathrm{mile}$ ).

In Scenario 6 the left shoulder lane downstream of the incident site was opened just for one hour following the onset of the incident. For this scenario, the simulation results show that the average network speed increased by $21 \%$ (from $25.1 \mathrm{mph}$ to $30.3 \mathrm{mph}$ ), and the average delay time decreased by $31 \%$, as compared to Scenario 5 . These gains resulted in network performance comparable to non-incident conditions. As expected, the savings in travel time and delay further increased when the temporary shoulder lane remained in operation for an extra hour following the incident removal (Scenario 7).

Overall, the network-wide results from the incident case study demonstrate the great potential operational benefits of the temporary shoulder lane use as a traffic management strategy in case of an incident.

\subsubsection{Cost-benefit analysis results}

A detailed cost-benefit analysis was performed to estimate economic impacts from possible deployment of temporary shoulder lane use strategies along the study segment of the I-65 freeway in Birmingham. The cost-benefit analysis compared anticipated costs and benefits from each of the study scenarios to the base case scenario (Scenario 1) in order to find the most cost-effective method.

From the CORSIM outputs for the different scenarios presented earlier, the fuel consumption, vehicle miles of travel, travel time, and emissions outputs were obtained and used to calculate Vehicle Operating Costs (VOC), value of time (VOT), accident costs, and emission costs. These costs were utilized to calculate and compare the benefit-cost ratios for different scenarios on an annual basis. Details are available in Sisiopiku et al, 2009b.

The benefit components for different scenarios are summarized in Table 5 and the resulting benefit-cost ratios for different scenarios are calculated and presented in Table 6. Table 5 shows clearly that VOC, VOT, accident costs and emission costs are lower when shoulder lane use is permitted. Furthermore, Table 6 indicates that the temporary use of the left shoulder lane along the I-65 study section during the 2 hour morning peak (Scenario 3 ) is expected to result in $\$ 12.6 \mathrm{M}$ in savings. Further savings can be realized by utilizing the shoulder lane for more extended periods of time (such as in Scenario 2). For alleviation of traffic congestion due to incidents, the most cost-effective option studied is provided by Scenario 7. The findings of benefit-cost analysis are in close agreement with those of the traffic impact analysis presented earlier. 


\begin{tabular}{|c|c|c|c|c|}
\hline \multicolumn{5}{|c|}{ Shoulder Lane Operation- Normal Conditions } \\
\hline Scenario & $\begin{array}{c}\text { VOC [Mil } \\
\text { \$/year] }\end{array}$ & $\begin{array}{c}\text { VOT [Mil } \\
\text { \$/year] }\end{array}$ & $\begin{array}{c}\text { Accident Cost [Mil } \\
\text { \$/year] }\end{array}$ & $\begin{array}{c}\text { Emission Cost [Mil } \\
\text { \$/year] }\end{array}$ \\
\hline 1 & 7.607 & 34.213 & 11.226 & 0.0043 \\
\hline 2 & 5.881 & 19.964 & 11.645 & 0.0041 \\
\hline 3 & 6.304 & 22.563 & 11.538 & 0.0042 \\
\hline 4 & 7.519 & 32.867 & 11.226 & 0.0043 \\
\hline 5 & 7.975 & 39.662 & 10.826 & 0.0044 \\
\hline 6 & 7.632 & 34.719 & 11.173 & 0.0043 \\
\hline 7 & 6.880 & 27.498 & 11.557 & 0.0042 \\
\hline
\end{tabular}

Table 5. Benefit Components for Different Scenarios.

\begin{tabular}{|c|c|c|c|c|}
\hline \multicolumn{7}{|c|}{ Shoulder Lane Operation- Normal Condition } \\
\hline Scenario & $\begin{array}{c}\text { Total Costs } \\
{[\text { M \$/year] }}\end{array}$ & $\begin{array}{c}\text { Total Benefit } \\
\text { Components [M } \\
\text { \$/year] }\end{array}$ & $\begin{array}{c}\text { Total Benefits with respect } \\
\text { to Base Case [M\$/year] }\end{array}$ & B/C Ratios \\
\hline 1 (Base) & 0.043 & 53.050 & - & 13.87 \\
\hline 2 & 1.122 & 37.494 & 15.556 & 11.27 \\
\hline 3 & 1.122 & 40.409 & 12.641 & 3.75 \\
\hline 4 & 1.434 & 51.613 & 1.434 & - \\
\hline 5 (Base) & 0.043 & 58.467 & 4.939 & 11.31 \\
\hline 6 & 1.108 & 53.528 & 12.528 & 4.46 \\
\hline 7 & 1.108 & 45.939 & & \\
\hline
\end{tabular}

Table 6. Benefit/Cost Ratios for Different Scenarios. 


\subsection{Case study summary findings}

Simulation analysis was performed to quantify the potential benefits of a temporary left shoulder lane use system on a segment of I-65 in Birmingham in response to recurrent and non-recurrent congestion. The results from the simulation analysis, coupled with findings from a cost-benefit analysis, were used to demonstrate the potential of the strategy to improve traffic operations and justify the need for deployment of the proposed strategy at the study location.

It was found that the use of temporary shoulder lanes can have a very positive impact on traffic operations along I-65 when implemented in response to both recurrent- and/or non-recurrent congestion. In this study, the temporary use of the left northbound shoulder lane for 2 hours during the morning peak (Scenario 3) resulted in a reduction in the total network travel time by $34 \%$ and delay by $71 \%$ compared to current operations (Scenario 1).

The use of right shoulder lanes upstream of exit ramps tested in this study provide some relief but had far less impact on network performance, compared to the continuous left shoulder lane usage. These results clearly indicate the tremendous potential of temporary shoulder lane use as an active traffic management tool for addressing recurrent congestion along I-65.

It was also found that considerable improvements in traffic operations can be achieved by utilizing the temporary shoulder lane downstream of an incident as an ATM measure. In the Birmingham study and under incident conditions, the utilization of the temporary shoulder lane resulted in an increase in average network speed by $21 \%$ and a decrease in average delay time by $31 \%$, as compared to the do-nothing approach. These gains are significant and provide further proof of the potential of temporary shoulder lane use within the ATM context as a tool for incident management.

The results from the benefit-cost analysis provide further justification for the use on temporary shoulder lanes. It can be seen that the total benefits from implementation of this strategy outweigh the total costs, which further confirms that the temporary shoulder lane use treatment is an economically viable solution both in the short and long terms.

\section{Conclusions and recommendations}

Overall, ATM seeks to introduce new congestion management strategies to the U.S. while enhancing the effectiveness of existing strategies. It should be viewed as the next logical step in the evolution of congestion management in this country rather than a radical change from previous practice. The European experience with ATM clearly demonstrates its positive impacts on traffic operations and safety and thereby, its tremendous potential for alleviating traffic congestion in the US.

However, the implementation of ATM is a significant investment so the potential benefits would have to be clearly defined and sufficient to justify the costs. To better assess potential costs and gains, careful screening of candidate test sites should take place first, followed by detailed assessment of operational and cost impacts from implementation. This practice will 
help identify opportunities and impediments from implementation, and document technology, policy, and other needs.

The success of implementation of ATM greatly depends on public support for the project and positive public perception. Thus, the role of public education in the early planning stage is critical and should not be overlooked. Focus groups, open public discussion forums, public information sessions, and media coverage are useful tools that can assist local agencies to obtain input from the public and other local stakeholders and educate the road users about their rights and responsibilities as they use the new ATM systems.

\section{Acknowledgment}

The authors gratefully acknowledge the Urban Transportation Center for Alabama for the financial support for this research. Moreover, the contributions of Mrs. Germin Fadel, Ms. Ozge Cavusoglu, Mr. Andy Sullivan and Dr. Saiyid Sikder to the Birmingham case study are greatly appreciated.

\section{References}

Berman, W., Differt, D. H., Aufschneider, K., DeCorla-Souza, P., Flemer, A., Hoang, L. T., Hull R., Schreffler E., and Zammit, G. (2006). Managing Travel Demand: Applying European Perspectives to U.S. Practice. Washington, DC: Federal Highway Administration.

FHWA (2003). Freeway Management and Operations Handbook -Roadway Improvements. Office of Transportation Management. Washington, D.C.

FHWA (1994). IVHS Institutional Issues and Case Studies. U.S. Department of Transportation. Cambridge, MA: Federal Highway Administration.

MnDOT (2010). “Minnesota's Smart Lanes Go Live July 29”, Retrieved May, 2011, from Minnesota Department of Transportation: http://www.dot.state.mn.us/metro/news/10/07/28smartlanes.html

Mirshahiet, M., Obenberge, J., Fuhs, C.A., Howard, C.E., Krammes, R.A., \& Kuhn, B. T. (2007). Active Traffic Management: The Next Step in Congestion Management. Washington, DC: Federal Highway Administration, FHWA-PL-07-012.

NCDOT (n.d.). High Occupancy Vehicle (HOV). Retrieved December 28, 2008, from North Carolina Department of Transportation: http://www.ncdot.org/projects/HOV/

PBS\&J. (2009). Tier 1 Alternatives Evaluation:I-65 / US 31 Mobility Matters Project. PBS\&J Team Project.

Sisiopiku, V.P., Cavusoglu, O., and Fadel, G. (2009). Active Traffic Management Opportunites and Challenges for Implementaion: ITE Technical Confrerence and Exhibit Compendium of Technical Papers, Phoenix, AZ.

Sisiopiku, V.P., Sullivan, A., Fadel, G., and Sikder, S. (2009b). Implementing Active Traffic Management Strategies in the U.S. Final Report to the University Transportation Center for Alabama. 
Sisiopiku, V.P., and Cavusoglu, O. (2008). Operational Impacts from Managed Lanes Implementation in Birmingham: ITE Annual Meeting and Exhibit Compendium of Technical Papers, Anaheim, CA.

Stone, C., Hammond, P., and Lenzi, J. (2007). Active Traffic Management: The Next Step in Congestion Management. Washington: Washington State Department of Transportation.

Tignor, S. C., Brown, L. L., Butner, J. L., Cunard, R., Davis, S. C., Hawkins, H. G., et al. (1999). Innovative Traffic Control Technology and Practice in Europe. Washington, D.C.: Federal Highway Administration. 


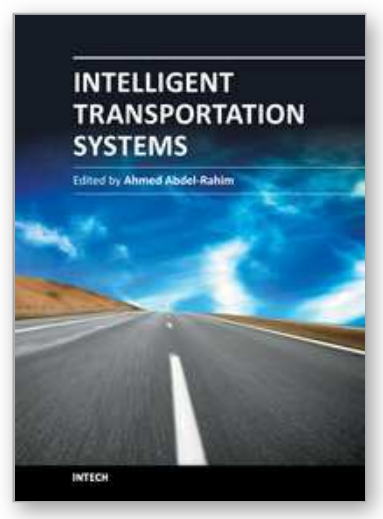

\author{
Intelligent Transportation Systems \\ Edited by Dr. Ahmed Abdel-Rahim
}

ISBN 978-953-51-0347-9

Hard cover, 206 pages

Publisher InTech

Published online 16, March, 2012

Published in print edition March, 2012

Intelligent Transportation Systems (ITS) have transformed surface transportation networks through the integration of advanced communications and computing technologies into the transportation infrastructure. ITS technologies have improved the safety and mobility of the transportation network through advanced applications such as electronic toll collection, in-vehicle navigation systems, collision avoidance systems, and advanced traffic management systems, and advanced traveler information systems. In this book that focuses on different ITS technologies and applications, authors from several countries have contributed chapters covering different ITS technologies, applications, and management practices with the expectation that the open exchange of scientific results and ideas presented in this book will lead to improved understanding of ITS technologies and their applications.

\title{
How to reference
}

In order to correctly reference this scholarly work, feel free to copy and paste the following:

Virginia P. Sisiopiku (2012). Active Traffic Management as a Tool for Addressing Traffic Congestion, Intelligent Transportation Systems, Dr. Ahmed Abdel-Rahim (Ed.), ISBN: 978-953-51-0347-9, InTech, Available from: http://www.intechopen.com/books/intelligent-transportation-systems/active-traffic-management-as-a-tool-foraddressing-traffic-congestion-

\section{INTECH}

open science | open minds

\author{
InTech Europe \\ University Campus STeP Ri \\ Slavka Krautzeka 83/A \\ 51000 Rijeka, Croatia \\ Phone: +385 (51) 770447 \\ Fax: +385 (51) 686166 \\ www.intechopen.com
}

\author{
InTech China \\ Unit 405, Office Block, Hotel Equatorial Shanghai \\ No.65, Yan An Road (West), Shanghai, 200040, China \\ 中国上海市延安西路65号上海国际贵都大饭店办公楼405单元 \\ Phone: +86-21-62489820 \\ Fax: +86-21-62489821
}


(C) 2012 The Author(s). Licensee IntechOpen. This is an open access article distributed under the terms of the Creative Commons Attribution 3.0 License, which permits unrestricted use, distribution, and reproduction in any medium, provided the original work is properly cited. 